\title{
Low to moderate lifetime alcohol consumption is associated with less advanced stages of fibrosis in non-alcoholic fatty liver disease
}

Hannes Hagström, Patrik Nasr, Mattias Ekstedt, Stergios Kechagias, Kristina Onnerhag, Emma Nilsson, Fredrik Rorsman, Reza Sheikhi, Hanns-Ulrich Marschall, Rolf Hultcrantz and

Per Stal

\section{Journal Article}

\section{Tweet}

N.B.: When citing this work, cite the original article.

This is an electronic version of an article published in:

Hannes Hagström, Patrik Nasr, Mattias Ekstedt, Stergios Kechagias, Kristina Onnerhag, Emma Nilsson, Fredrik Rorsman, Reza Sheikhi, Hanns-Ulrich Marschall, Rolf Hultcrantz and Per Stal, Low to moderate lifetime alcohol consumption is associated with less advanced stages of fibrosis in non-alcoholic fatty liver disease, Scandinavian Journal of Gastroenterology, 2017. 52(2), pp.159-165.

Scandinavian Journal of Gastroenterology is available online at informaworldTM:

http://dx.doi.org/10.1080/00365521.2016.1239759

Copyright: Taylor \& Francis: STM, Behavioural Science and Public Health Titles http://www.tandf.co.uk/journals/default.asp

Postprint available at: Linköping University Electronic Press

http://urn.kb.se/resolve?urn=urn:nbn:se:liu:diva-134618 


\section{Low to moderate lifetime alcohol consumption is associated with less advanced stages of fibrosis in non-alcoholic fatty liver disease}

Hannes Hagström ${ }^{1}$, Patrik Nasr² ${ }^{2}$ Mattias Ekstedt ${ }^{2}$, Stergios Kechagias ${ }^{2}$, Kristina Önnerhag ${ }^{3}$, Emma Nilsson ${ }^{3}$, Fredrik Rorsman ${ }^{4}$, Reza Sheikhi ${ }^{4}$, Hanns-Ulrich Marschall $^{5}$, Rolf Hultcrantz ${ }^{1}$, Per Stål ${ }^{1}$

${ }^{1}$ Centre for Digestive Diseases, Division of Hepatology, Karolinska University Hospital, Stockholm, Sweden and Department of Medicine, Huddinge, Karolinska Institutet, Stockholm, Sweden

${ }^{2}$ Department of Gastroenterology and Hepatology and Department of Medical and Health Sciences, Linköping University, Linköping, Sweden

${ }^{3}$ Department of Gastroenterology and Hepatology, Skåne University Hospital Malmö/Lund, Sweden

${ }^{4}$ Department of Gastroenterology and Hepatology, Uppsala University Hospital, Uppsala, Sweden

${ }^{5}$ Sahlgrenska Academy, Institute of Medicine, Department of Molecular and Clinical Medicine, University of Gothenburg, Gothenburg, Sweden

*Correspondence and reprint requests:

Hannes Hagström, Centre for Digestive Diseases, Division of Hepatology, Karolinska University Hospital, 14186 Stockholm, Sweden

Phone: +46 (0) 85858 2308, Fax: +46 (0) 858582335

E-mail: hannes.hagstrom@ki.se

Running head: Alcohol consumption in NAFLD 
Abbreviations: NAFLD, non-alcoholic fatty liver disease. NASH, non-alcoholic steatohepatitis. LDH, lifetime drinking history. OR, odds ratio. CI, confidence interval. PEth, phosphatidyl ethanol.

Total word count (introduction to discussion): 3039. Abstract: 240. Tables: 4.

Figures: 1 . Character count for title: 133

\section{Author contributions:}

Study conception and design: HH, PS

Acquisition of data: HH, PN, ME, SK, KÖ, EN, FR, RS, HUM, RH, PS

Statistical analysis: $\mathrm{HH}$

Analysis and interpretation of data: $\mathrm{HH}, \mathrm{PS}$

Drafting of manuscript: $\mathrm{HH}$

Critical revision: HH, PN, ME, SK, KÖ, EN, FR, RS, HUM, RH, PS

Guarantor of article: $\mathrm{HH}$

Grant Support (Funding): HH was supported by grants from the Stockholm County

Council (ALF projects 20140329 and 20150403) and from the Royal Swedish

Academy of Sciences Foundations (project ME2015-0011)

PS was supported by grants from the Swedish Society of Medicine (Gastroenterology

Fund), Ruth and Richard Julins Fund, and ALF 2015403. 


\section{Abstract}

Background and aim: Moderate alcohol consumption has been associated with a lower risk of disease severity in non-alcoholic fatty liver disease (NAFLD). It is unclear if this reflects current or lifetime drinking, or can be attributed to confounders such as diet and exercise. We evaluated the impact of lifetime alcohol consumption on fibrosis severity in NAFLD.

Methods: We prospectively enrolled 120 subjects with biopsy-proven NAFLD and through detailed questionnaires examined lifetime alcohol consumption, diet and physical activity. Main outcome measures were odds ratios (OR) for fibrosis stage, calculated through ordinal regression after adjustment for body mass index, diabetes mellitus type 2, smoking and age at biopsy. A biomarker for recent alcohol consumption, phosphatidyl ethanol (PEth) was sampled.

$\underline{\text { Results: }}$ An increase in median weekly alcohol consumption to a maximum of 13 drinks per week was associated with lower fibrosis stage (adjusted OR for each incremental unit, 0.86; 95\% CI, 0.76-0.97; $\mathrm{p}=0.017$ ). The lowest risk for fibrosis was found with the lowest odds seen in the top quartile of alcohol consumption (aOR 0.23; 95\% CI 0.08-0.66; $\mathrm{p}=0.006$ ). Adding soft drink and coffee consumptions, and physical activity to the model did not change the estimates. Subjects with PEth $\geq 0.3$ $\mu \mathrm{mol} / \mathrm{L}$ had higher ORs for a higher fibrosis stage (aOR 2.77; 95\% CI 1.01-7.59; $\mathrm{p}=0.047)$.

Conclusion: Lifetime alcohol consumption with up to 13 units per week is associated with lower fibrosis stage in NAFLD. Elevated PEth is associated with higher stages of fibrosis.

Keywords: NAFLD, NASH, alcohol, lifetime alcohol consumption, fibrosis stage 


\section{Introduction}

Non-alcoholic fatty liver disease (NAFLD) is the world's most prevalent liver disease [1]. The majority of subjects with NAFLD have a benign course of disease, however some subjects develop non-alcoholic steatohepatitis (NASH) and fibrosis [2, 3]. It is difficult to identify individuals with fibrosis, which can lead to cirrhosis and hepatocellular carcinoma [4, 5].

The impact of alcohol consumption on NAFLD is controversial. First, the main cause of death in NAFLD is cardiovascular disease [6], and moderate alcohol consumption has been suggested to reduce the risk of death in cardiovascular disease [7], why it could be argued that alcohol could be beneficial in NAFLD. Secondly, previous studies have shown an association between low-to-moderate alcohol consumption and lower risk for NAFLD, NASH and fibrosis [8, 9, 10]. Also, regular consumption of moderate amounts of alcohol, $150 \mathrm{ml}$ of red wine per day for 90 days did not induce hepatic steatosis in healthy subjects [11]. However, population-based studies have indicated an interaction on the risk of liver damage between a high body mass index (BMI), which is highly associated with NAFLD [12], and alcohol consumption $[13,14]$.

Previous studies on alcohol consumption in NAFLD have defined alcohol consumption as current consumption, not taking the lifetime amount of alcohol consumption into account. This approach may misclassify subjects with a history of alcohol dependency, who have eventually stopped drinking, as non-drinkers. Furthermore, most studies have been unable to adjust for potential confounders, including BMI and presence of diabetes. In addition, lifestyle factors such as consumption of soft drinks [15] and coffee [16] as well as physical activity [17] that 
might have disease-modifying properties, have not been investigated as potential confounders.

The aim of this study was to examine the impact of lifetime alcohol consumption on the severity of fibrosis stage and presence of NASH in NAFLD, after adjusting for potential confounders. 


\section{Material and methods}

We performed a prospective study of subjects who underwent liver biopsy as part of a NAFLD/NASH severity work-up at five university hospitals in Sweden: Karolinska University Hospital(N=73), Linköping University Hospital (N=26), Sahlgrenska University Hospital (N=4), Uppsala University Hospital (N=9) and Skåne University Hospital $(\mathrm{N}=8)$. Other liver diseases were excluded before biopsy in all subjects as part of the routine work-up. Patients who reported consuming more than 14 units of alcohol per week were excluded.

At the occasion of the biopsy, blood was drawn after an overnight fast for biochemical analyses, including markers of glucose metabolism, inflammation, lipid profile and markers of alcohol consumption. Also, a standard oral glucose tolerance test was performed in subjects without known diabetes mellitus. Furthermore, four questionnaires were used, including the lifetime drinking history (LDH) questionnaire [18], the alcohol-use disorders identification test (AUDIT) questionnaire, a standard screening instrument for detecting risky and harmful alcohol use [19], a food frequency questionnaire [20], and a questionnaire grading physical activity, as described below.

\section{Liver biopsies}

All biopsies were centrally read by an expert liver pathologist (R.H.), blinded to subject data including the original pathology report, and scored according to the NAFLD Activity Score (NAS) [21] as well as the Steatosis Activity Fibrosis (SAF) system [22]. Presence of NASH was defined according to the fatty liver inhibition of progression (FLIP) algorithm, as the presence of both fat, lobular inflammation and ballooning [23]. Fibrosis stage was scored according to the NASH CRN fibrosis 
scoring system as 0-4 [21]. Only biopsies with $\geq 7$ portal tracts were included in the study.

\section{Alcohol consumption}

We used the LDH questionnaire to assess lifetime alcohol consumption. In this tool, subjects report alcohol consumption during different periods of life. For each period, the subject reports the mean number of days per year he or she drank any amount of alcohol, and the mean number of drinks per drinking day. In the same way, binge drinking, defined as drinking equal to or more than five units of alcohol per day is reported. One unit of alcohol as defined in Sweden, containing 12 grams of alcohol [24], corresponds to $330 \mathrm{ml}$ of beer, $150 \mathrm{ml}$ of wine or $40 \mathrm{ml}$ of spirits. The age at the first consumed alcoholic drink, as well as age at the last consumed alcoholic drink if the subject had stopped drinking is noted. This data was used to calculate the number of drinking years per patient.

Total lifetime consumption of alcohol was calculated and is presented as the median number of drinks per week from the age of onset of alcohol consumption. Other measures of alcohol consumption included total alcohol consumption during the last year and total alcohol intake during the last week. Also,drinks per drinking day were defined as the median number of drinks per occasion of drinking alcohol. Gram-years of alcohol consumption were calculated by multiplying the amount of alcohol consumed in grams per day with the number of drinking years.

Relying on self-reported alcohol consumption has the risk of misclassifying subjects who underreport their alcohol intake. One way to control for this is the use of alcohol-related biomarkers. A relatively new biomarker is phosphatidyl ethanol (PEth) [25]. We stratified the cohort on the level of their PEth values, using a cut-off 
of $0.3 \mu \mathrm{mol} / \mathrm{L}$ as per the manufacturers recommendations to identify subjects consuming more than moderate amounts of alcohol [26]. Subjects with PEth values $\geq$ $0.3 \mu \mathrm{mol} / \mathrm{L}$ were not evaluated in the primary statistical model, but used in sensitivity analyses and for descriptive statistics. In sensitivity analysis, we used different cutoffs of PEth, 0.1 and 0.2 respectively.

\section{Potential confounding factors}

Diabetes mellitus type 2 was defined as previously diagnosed and/or pharmacological treatment for diabetes. In subjects without known diabetes, a standard $75 \mathrm{~g}$ oral glucose tolerance test was performed. Subjects with a fasting capillary glucose $\geq 126$ $\mathrm{mg} / \mathrm{dL}$ or with a capillary glucose two hours after the glucose load $\geq 200 \mathrm{mg} / \mathrm{dL}$ were classified as having diabetes mellitus type 2 . Blood pressure was measured after a five-minute resting period, and arterial hypertension was defined as a pre-existing diagnosis of this, or a finding of a blood pressure of above 140/90 mmHg on two separate occasions. Height and weight as well as hip and waist measurements were recorded without shoes and with light clothing.

Coffee and soft drink servings per week were estimated using a quantitative food frequency questionnaire, measured on a continuous scale. One serving was defined as $200 \mathrm{ml}$ of each beverage. Physical activity during the last year before biopsy was measured using a semi-quantitative questionnaire, where leisure-time physical activity was scored on a scale of 1-6, were 1 indicated very low physical activity and 6 indicated hard aerobic training, performed on a regular basis, at least once per week. Smoking was classified as if the subject had ever or never been smoking.

\section{Statistical analyses}


Differences between continuous variables were analysed using the Mann-Whitney Utest, and between categorical variables using Fischer's Exact test. We applied an ordinal logistic regression model to estimate the effect of alcohol consumption on the stage of fibrosis, and a logistic regression model to estimate the effect of alcohol consumption on the presence of NASH. In a separate model, we divided the cohort into quartiles of weekly alcohol consumption and examined the association with fibrosis stage, using the second quartile of alcohol consumption as the reference category. Data regarding gram-years was analysed dichotomized on the median value. The multivariate models included lifetime alcohol consumption per drinking week as the primary independent variable, and the full model was adjusted for age at biopsy, diabetes mellitus type 2, arterial hypertension, BMI and smoking status, dichotomized as ever or never. Data are presented as odds ratios (OR) with 95\% confidence intervals (CI), with a significance level of 0.05. All analyses were performed using STATA version 12.1 (StataCorp, College Station, Texas, US).

\section{Ethical considerations}

The Regional Ethics Committee at Karolinska Institutet approved the study (Dnr 2012/1686-32; 03-Jan-2012), and all subjects gave written informed consent. 


\section{Results}

Between 2012 and 2015, 139 subjects were identified and gave informed consent.. Furthermore, 13 subjects had a PEth value of $\geq 0.3 \mu \mathrm{mol} / \mathrm{L}$ (median 0.52 , range 0.31 1.05), indicating more pronounced recent alcohol consumption than reported at the visit or in the questionnaires; these 13 subjects were evaluated separately in the regression analyses.

Of the 107 subjects with complete data, 20 had fibrosis stage 0,42 had stage 1,17 had stage 2, 13 had stage 3 and 15 had stage 4.65 subjects (61\%) had NASH according to the FLIP algorithm [23]. Participant characteristics on the entire cohort are presented in Table 1, and stratified on the median lifetime alcohol consumption in table 2 .

\section{Alcohol consumption}

Reported lifetime alcohol consumption was low, with a median lifetime consumption of 1.1 units of alcohol per week (range $0-13.2$ ). Data on patterns of alcohol consumption are presented in table 1, and stratified on the median lifetime alcohol consumption in table 2.

\section{Impact of alcohol consumption on fibrosis stage}

Up to a maximum of 13 reported drinks per week, each additional unit in alcohol consumption per week was associated with decreasing odds ratios (OR) for having a higher fibrosis stage, both in the univariate model (OR, 0.86; 95\% confidence interval [CI], 0.77-0.97; $\mathrm{p}=0.016$ ) and in the multivariate model (adjusted [a] OR, 0.86; 95\% CI, 0.76-0.97; $\mathrm{p}=0.017)$. A scatterplot of reported lifetime alcohol consumption per week versus the stage of fibrosis is presented in Figure 1. Only measures of lifetime 
alcohol intake, and no other measures of alcohol intake, were associated with fibrosis stage (table 3).

When dividing the cohort into quartiles based on lifetime weekly alcohol intake, the first quartile consumed between 0-0.3 units of alcohol per week, the second consumed between 0.3-1.0 units of alcohol per week, the third quartile consumed between 1.0-3.1 units of alcohol per week and the fourth quartile consumed between 3.1-13.3 units of alcohol per week. Using persons consuming alcohol in the second quartile as the reference group, we found that increasing alcohol intake was associated with reduced risk for a higher fibrosis stage for the third quartile (aOR 0.38, 95\%CI 0.15-0.99, $\mathrm{p}=0.05$ ) and for the fourth quartile (aOR 0.23, 95\%CI 0.08-0.66, $\mathrm{p}=0.006$ ) but not for the first quartile (aOR 0.70, 95\%CI 0.27-1.77, $\mathrm{p}=0.45$ ).

Binge drinking was not associated with fibrosis stage (aOR 0.97; 95\% CI 0.931.01; $\mathrm{p}=0.11)$. When dividing binge drinking into quartiles $(0,0.1-0.9,0.9-4.0,4.0-$ 45), the highest quartile ( $>4$ episodes per year, $N=27$ ) did not have a higher fibrosis stage than the three lower quartiles (1.5 vs. $1.8, \mathrm{p}=0.38)$.

The thirteen subjects with PEth values $\geq 0.3 \mu \mathrm{mol} / \mathrm{L}$ had almost three-times increased ORs for having higher more advanced stages of fibrosis than subjects with PEth $<0.3 \mu \mathrm{mol} / \mathrm{L}$, both in the univariate (OR 2.76; 95\% CI 1.06-7.21; $\mathrm{p}=0.038$ ) and in the multivariate models (aOR 2.77; 95\% CI 1.01-7.59; $\mathrm{p}=0.047$ ). Subjects with intermediate PEth values (0.05-0.3 $\mu \mathrm{mol} / \mathrm{L})$ did not have an increased risk for a higher fibrosis stage, compared to subjects with PEth $<0.05 \mu \mathrm{mol} / \mathrm{L}$ (OR 0.80; 95\% CI 0.302.10; $\mathrm{p}=0.65)$. Using different cut-offs of PEth did not change the estimates significantly (data not shown).

Impact of potential confounders on fibrosis stage 
Neither soft drink consumption, coffee consumption or extent of physical activity was associated with a higher fibrosis stage (data not shown). Adding soft drink and coffee consumption and physical activity to the model did not change the estimates significantly (OR 0.87; 95\% CI 0.76-1.00; p=0.05). Crude ORs for all tested potential confounders, and adjusted ORs for covariates included in the final models are presented in Table 3.

\section{Impact of all variables on presence of NASH}

Crude ORs for associations of the study variables with the presence of NASH, as defined by the FLIP algorithm, are presented in Table 4. No association for any studied lifetime alcohol consumption parameter with NASH was found.

Subjects with PEth $\geq 0.3 \mu \mathrm{mol} / \mathrm{L}$ had overall higher NAS (5.6 vs. 4.2, $\mathrm{p}=0.004$ ) and a substantially increased risk of NAS $\geq 5$, both in the univariate (OR 7.58; 95\% CI 1.60-35.87 $\mathrm{p}=0.01$ ) and in the multivariate analysis (aOR 17.09; 95\% CI 2.03143.56, $\mathrm{p}=0.009)$.

\section{Blood parameters}

Subjects who consumed more than the median amount of 1.1 units of alcohol per week had lower values of inflammatory markers TNF (median 7.9 vs. 9.7 ng/L, $\mathrm{p}=0.05$ ) and highly sensitive CRP (median 1.5 vs. $2.7 \mathrm{mg} / \mathrm{L}, \mathrm{p}=0.004$ ), but slightly higher values of total cholesterol (193 vs. $170 \mathrm{mg} / \mathrm{dL}, \mathrm{p}=0.03$ ). There were no significant differences in other metabolic markers including HOMA-IR or transaminases (table 2). 


\section{Discussion}

This is the hitherto largest study that examines the association of lifetime alcohol consumption with disease severity in NAFLD using the highly detailed LDH questionnaire and adjusting for potential confounding factors. Our main finding was that low to moderate alcohol consumption, up to a maximum of 13 units per week, was associated with lower stages of liver fibrosis, even after adjusting for confounders. The lowest risk for fibrosis was found in the top quartile of lifetime alcohol consumption, consuming 3-13 drinks per week. In contrast, subjects with biochemical signs of more than moderate current alcohol consumption, as indicated by serum PEth levels above the cut-off of $0.3 \mu \mathrm{mol} / \mathrm{L}$, had almost three-times increased ORs for higher stages of fibrosis (OR 2.77; 95\% CI 1.01-7.59; p=0.047), indicating that a high consumption of alcohol increases the risk for fibrosis progression in NAFLD. Of note, PEth is not yet applied internationally as an integral marker of recent alcohol consumption, and has not been used in previous studies on NAFLD. Thus, these thirteen subjects would have been included as unbiased NAFLD cases in any other study not using PEth. In a previous randomized controlled trial, consumption of $150 \mathrm{ml}$ of red wine for women and $300 \mathrm{ml}$ for men per day for three months did not elevate PEth $>0.3 \mu \mathrm{mol} / \mathrm{L}$ in a single subject [27], indicating that these 13 subjects potentially drank more than these amounts.

Strengths of this study include the size of the cohort, the detailed methodology to define the exposure of lifetime alcohol intake, data on potential confounders and the gold standard diagnosis of biopsy-verified NASH and fibrosis stage, evaluated by a single, blinded specialized liver pathologist. Furthermore, this was a multi-centre study performed in university hospitals where concomitant liver disease was carefully 
excluded, which is likely to reduce the risk of selection bias and to increase the external validity of the study.

Limitations include the use of retrospective questionnaires to study alcohol consumption, which inevitably infers the risk of bias - especially recall bias. However, the LDH questionnaire has been validated [28] and shown to have a high test-retest reliability [29]. In addition, removing subjects with a PEth of $\geq 0.3 \mu \mathrm{mol} / \mathrm{L}$ from the statistical models likely reduces bias. Also, the finding of a median consumption of 1.1 units per week is well in line with findings from a representative sample of the general Swedish population, where $92 \%$ of women and $85 \%$ of men were found to consume less than 21 grams of alcohol per week, roughly equal to 2 units [24]. Conversely, the finding that the subgroup with PEth values of $\geq 0.3$ $\mu \mathrm{mol} / \mathrm{L}$ had higher ORs for a higher fibrosis stage is well in line with current evidence that more than moderate alcohol consumption is harmful for the liver [30, 31, 32]. This group of subjects probably underreported their current alcohol intake. Furthermore, the sample size of the current study was rather small, disallowing us to for example stratify results on sex.

A number of cross-sectional studies has recently reported that low to moderate current alcohol consumption is associated with a lower risk of NAFLD [10] and also of NASH [9]. Dunn et al used the LDH to exclude lifetime drinkers from their nondrinker population, but did not report lifetime drinking data [9]. Only one previous study has used the LDH questionnaire to fully examine the effect of lifetime alcohol consumption on NAFLD severity. Similar to our study, subjects in the study by Kwon et al who consumed more than the median lifetime amount of 24 gram-years of 
alcohol had lower odds ratio for fibrosis stage 3-4 compared to subjects who consumed less than the median amount [33]. However, in that study, only 77 subjects were included, and alcohol consumption was reported at as low as 23 gram-years, compared to 56 gram-years in our study, which is in line with the normal mean alcohol consumption in Sweden [24]. In addition, we evaluated confounders such as consumption of soft drinks and coffee, but found no association to increased fibrosis or NASH.

In contrast to previous studies [9, 10], we did not find different alcohol consumption patterns between subjects with and without NASH. Alcohol consumption during the last week before biopsy was low in our cohort (median 0 units), which might have blurred a potentially protective effect of low to moderate alcohol consumption on NASH that was observed in other studies [9]. Conversely, subjects with PEth $\geq 0.3 \mu \mathrm{mol} / \mathrm{L}$ had higher NAS, indicating that a current higher than moderate alcohol consumption is associated with a more pronounced disease activity. This finding suggests a J-like risk profile for alcohol consumption and liver fibrosis, passing from a potentially beneficial to a potentially harmful effect at around 2-3 drinks per day. Interestingly, this is also the pattern for alcohol consumption and mortality. For example, Thun et al found a reduced risk of overall mortality for persons who reported at least one drink per day in 490.000 US adults, and an increased risk of overall mortality for persons consuming more than three drinks per day [7]. In a meta-analysis of the effect of alcohol consumption on cardiovascular disease, the main finding was that the lowest risk for coronary heart disease mortality was seen in subjects drinking 1-2 units of alcohol per day [34]. Interestingly, subjects who consumed more than the median amount of alcohol (1.1 unit/week) had lower inflammatory markers including TNF and highly sensitive-CRP 
compared to subjects who consumed less than the median. This might indicate a potential anti-inflammatory potential of alcohol, and is in agreement with a $52 \%$ lower risk of developing rheumatoid arthritis for women who consume more than three units of alcohol per week [35].

We conclude that an alcohol intake of up to 13 units per week is inversely associated with the risk for a higher fibrosis stage, and that high levels of PEth are associated with higher stages of fibrosis in NAFLD. 
Conflicts of interest: No author reports conflicts of interest for this study. 


\section{References}

1. Loomba R, Sanyal AJ. The global NAFLD epidemic. Nature reviews Gastroenterology \& hepatology. 2013;10:686-90. Epub 2013/09/18.

2. Adams LA, Sanderson S, Lindor KD, Angulo P. The histological course of nonalcoholic fatty liver disease: a longitudinal study of 103 patients with sequential liver biopsies. Journal of hepatology. 2005;42:132-8.

3. Singh S, Allen AM, Wang Z, Prokop LJ, Murad MH, Loomba R. Fibrosis progression in nonalcoholic fatty liver vs nonalcoholic steatohepatitis: a systematic review and meta-analysis of paired-biopsy studies. Clinical gastroenterology and hepatology : the official clinical practice journal of the American Gastroenterological Association. 2015;13:643-54.e1-9; quiz e39-40. Epub 2014/04/29.

4. Michelotti GA, Machado MV, Diehl AM. NAFLD, NASH and liver cancer. Nature reviews Gastroenterology \& hepatology. 2013;10:656-65. Epub 2013/10/02. 5. Ascha MS, Hanouneh IA, Lopez R, Tamimi TA, Feldstein AF, Zein NN. The incidence and risk factors of hepatocellular carcinoma in patients with nonalcoholic steatohepatitis. Hepatology. 2010;51:1972-8.

6. Ekstedt M, Hagstrom H, Nasr P, Fredrikson M, Stal P, Kechagias S, Hultcrantz R. Fibrosis stage is the strongest predictor for disease-specific mortality in NAFLD after up to 33 years of follow-up. Hepatology. 2015;61:1547-54. Epub 2014/08/16.

7. Thun MJ, Peto R, Lopez AD, Monaco JH, Henley SJ, Heath CW, Jr., Doll R. Alcohol consumption and mortality among middle-aged and elderly U.S. adults. The New England journal of medicine. 1997;337:1705-14. Epub 1997/12/11. 8. Dunn W, Xu R, Schwimmer JB. Modest wine drinking and decreased prevalence of suspected nonalcoholic fatty liver disease. Hepatology. 2008;47:1947-54. Epub 2008/05/06.

9. Dunn W, Sanyal AJ, Brunt EM, Unalp-Arida A, Donohue M, McCullough AJ, Schwimmer JB. Modest alcohol consumption is associated with decreased prevalence of steatohepatitis in patients with non-alcoholic fatty liver disease (NAFLD). Journal of hepatology. 2012;57:384-91.

10. Sookoian S, Castano GO, Pirola CJ. Modest alcohol consumption decreases the risk of non-alcoholic fatty liver disease: a meta-analysis of 43175 individuals. Gut. 2014;63:530-2. Epub 2013/09/13.

11. Kechagias S, Zanjani S, Gjellan S, Leinhard OD, Kihlberg J, Smedby O, Johansson L, Kullberg J, Ahlstrom H, Lindstrom T, Nystrom FH. Effects of moderate red wine consumption on liver fat and blood lipids: a prospective randomized study. Annals of medicine. 2011;43:545-54. Epub 2011/05/24. 12. Younossi ZM, Koenig AB, Abdelatif D, Fazel Y, Henry L, Wymer M. Global Epidemiology of Non-Alcoholic Fatty Liver Disease-Meta-Analytic Assessment of Prevalence, Incidence and Outcomes. Hepatology. 2015. Epub 2015/12/29. 13. Ruhl CE, Everhart JE. Joint effects of body weight and alcohol on elevated serum alanine aminotransferase in the United States population. Clinical gastroenterology and hepatology : the official clinical practice journal of the American Gastroenterological Association. 2005;3:1260-8. Epub 2005/12/20. 
14. Liu B, Balkwill A, Reeves G, Beral V, Million Women Study C. Body mass index and risk of liver cirrhosis in middle aged UK women: prospective study. Br Med J. 2010;340:7.

15. Abid A, Taha O, Nseir W, Farah R, Grosovski M, Assy N. Soft drink consumption is associated with fatty liver disease independent of metabolic syndrome. Journal of hepatology. 2009;51:918-24. Epub 2009/09/22.

16. Bambha K, Wilson LA, Unalp A, Loomba R, Neuschwander-Tetri BA, Brunt EM, Bass NM. Coffee consumption in NAFLD patients with lower insulin resistance is associated with lower risk of severe fibrosis. Liver international : official journal of the International Association for the Study of the Liver. 2014;34:1250-8. Epub 2013/11/26.

17. Zelber-Sagi S, Nitzan-Kaluski D, Goldsmith R, Webb M, Zvibel I, Goldiner I, Blendis L, Halpern Z, Oren R. Role of Leisure-Time Physical Activity in Nonalcoholic Fatty Liver Disease: A Population-Based Study. Hepatology. 2008;48:1791-8.

18. Skinner HA, Sheu WJ. Reliability of alcohol use indices. The Lifetime Drinking History and the MAST. Journal of studies on alcohol. 1982;43:1157-70. Epub 1982/11/01.

19. Saunders JB, Aasland OG, Babor TF, Delafuente JR, Grant M. DEVELOPMENT OF THE ALCOHOL-USE DISORDERS IDENTIFICATION TEST (AUDIT) - WHO COLLABORATIVE PROJECT ON EARLY DETECTION OF PERSONS WITH HARMFUL ALCOHOL-CONSUMPTION .2. Addiction. 1993;88:791-804. 20. Khani BR, Ye W, Terry P, Wolk A. Reproducibility and validity of major dietary patterns among Swedish women assessed with a food-frequency questionnaire. The Journal of nutrition. 2004;134:1541-5. Epub 2004/06/03. 21. Kleiner DE, Brunt EM, Van Natta M, Behling C, Contos MJ, Cummings OW, Ferrell LD, Liu YC, Torbenson MS, Unalp-Arida A, Yeh M, McCullough AJ, Sanyal AJ, Nonalcoholic Steatohepatitis Clinical Research N. Design and validation of a histological scoring system for nonalcoholic fatty liver disease. Hepatology. 2005;41:1313-21.

22. Bedossa P, Poitou C, Veyrie N, Bouillot JL, Basdevant A, Paradis V, Tordjman J, Clement K. Histopathological algorithm and scoring system for evaluation of liver lesions in morbidly obese patients. Hepatology. 2012;56:1751-9. Epub 2012/06/19.

23. Bedossa P. Utility and appropriateness of the fatty liver inhibition of progression (FLIP) algorithm and steatosis, activity, and fibrosis (SAF) score in the evaluation of biopsies of nonalcoholic fatty liver disease. Hepatology. 2014;60:565-75. Epub 2014/04/23.

24. Wilén. Statistics Sweden, Living Conditions, Report no 114:

Use of alcohol and tobacco. 2007.

25. Helander A, Peter O, Zheng YF. Monitoring of the Alcohol Biomarkers PEth, CDT and EtG/EtS in an Outpatient Treatment Setting. Alcohol and Alcoholism. 2012;47:552-7.

26. Aradottir S, Asanovska G, Gjerss S, Hansson P, Alling C. PHosphatidylethanol (PEth) concentrations in blood are correlated to reported alcohol intake in alcohol-dependent patients. Alcohol and alcoholism (Oxford, Oxfordshire). 2006;41:431-7. Epub 2006/04/21.

27. Kechagias S, Dernroth DN, Blomgren A, Hansson T, Isaksson A, Walther L, Kronstrand R, Kagedal B, Nystrom FH. Phosphatidylethanol Compared with 
Other Blood Tests as a Biomarker of Moderate Alcohol Consumption in Healthy Volunteers: A Prospective Randomized Study. Alcohol and alcoholism (Oxford, Oxfordshire). 2015;50:399-406. Epub 2015/04/18.

28. Koenig LB, Jacob T, Haber JR. Validity of the lifetime drinking history: a comparison of retrospective and prospective quantity-frequency measures. Journal of studies on alcohol and drugs. 2009;70:296-303. Epub 2009/03/06. 29. Russell M, Marshall JR, Trevisan M, Freudenheim JL, Chan AW, Markovic N, Vana JE, Priore RL. Test-retest reliability of the cognitive lifetime drinking history. American journal of epidemiology. 1997;146:975-81. Epub 1997/12/24. 30. Westin J, Lagging LM, Spak F, Aires N, Svensson E, Lindh M, Dhillon AP, Norkrans G, Wejstal R. Moderate alcohol intake increases fibrosis progression in untreated patients with hepatitis $C$ virus infection. Journal of viral hepatitis. 2002;9:235-41.

31. Campbell S, Fletcher A, Russell RI. A sensitive, colorimetric, microtitre assay for alcohol dehydrogenase in standard endoscopic gastric biopsies. Clinica chimica acta; international journal of clinical chemistry. 2002;322:43-9.

32. Goh GB, Chow WC, Wang R, Yuan JM, Koh WP. Coffee, alcohol and other beverages in relation to cirrhosis mortality: the Singapore Chinese Health Study. Hepatology. 2014;60:661-9. Epub 2014/04/23.

33. Kwon HK, Greenson JK, Conjeevaram HS. Effect of lifetime alcohol consumption on the histological severity of non-alcoholic fatty liver disease. Liver international : official journal of the International Association for the Study of the Liver. 2014;34:129-35. Epub 2013/07/03.

34. Ronksley PE, Brien SE, Turner BJ, Mukamal KJ, Ghali WA. Association of alcohol consumption with selected cardiovascular disease outcomes: a systematic review and meta-analysis. Br Med J. 2011;342:13.

35. Di Giuseppe D, Alfredsson L, Bottai M, Askling J, Wolk A. Long term alcohol intake and risk of rheumatoid arthritis in women: a population based cohort study. Bmj. 2012;345:e4230. Epub 2012/07/12.

36. Ekstedt M, Franzen LE, Holmqvist M, Bendtsen P, Mathiesen UL, Bodemar G, Kechagias S. Alcohol consumption is associated with progression of hepatic fibrosis in non-alcoholic fatty liver disease. Scandinavian journal of gastroenterology. 2009;44:366-74. 
Tables.

\begin{tabular}{|c|c|c|}
\hline Variable & Median / N (\%) & Range \\
\hline Age at biopsy & 55.9 & $19.3-77.2$ \\
\hline Sex, $\mathrm{N}$ male (\%) & 83 (69) & \\
\hline \multicolumn{3}{|l|}{ Smoking, N (\%) } \\
\hline Never & $65(55)$ & \\
\hline Ever & $54(45)$ & \\
\hline $\begin{array}{l}\text { Coffee consumption } \\
\text { per week }\end{array}$ & 14 & $0-70$ \\
\hline $\begin{array}{l}\text { Soft drink consumption } \\
\text { per week }\end{array}$ & 0 & $0-56$ \\
\hline DM type 2, N (\%) & $49(41)$ & \\
\hline Hypertension, N (\%) & $62(52)$ & \\
\hline BMI & 29.9 & $20.3-44.3$ \\
\hline Waist (cm) & 106 & 86-139 \\
\hline Hip (cm) & 106 & $90-140$ \\
\hline Ferritin $(\mu \mathrm{g} / \mathrm{L})$ & 242 & 7-1804 \\
\hline ALT (IU/L) & 59 & 18-292 \\
\hline AST (IU/L) & 44 & $17-156$ \\
\hline Fasting Glucose (mg/dL) & 121 & 85-703 \\
\hline HOMA-IR & 9.4 & $1.5-389$ \\
\hline $\mathrm{HbA1c}(\mathrm{mmol} / \mathrm{mol})$ & 40 & 23-105 \\
\hline hS-CRP (mg/L) & 2 & $0.2-30$ \\
\hline Cholesterol (mg/dL) & 181 & 93-309 \\
\hline LDL (mg/dL) & 108 & $39-212$ \\
\hline HDL (mg/dl) & 42 & $12-89$ \\
\hline Triglycerides (mg/dL) & 159 & $42-478$ \\
\hline NAS $(0-8)$ & 4 & $1-8$ \\
\hline \multicolumn{3}{|l|}{ Fibrosis stage, N (\%) } \\
\hline 0 & $20(17)$ & \\
\hline 1 & 45 (38) & \\
\hline 2 & $21(18)$ & \\
\hline 3 & $17(14)$ & \\
\hline 4 & $17(14)$ & \\
\hline $\begin{array}{l}\text { Lifetime alcohol intake per week, } \\
\text { units }\end{array}$ & 1.1 & $0-13.2$ \\
\hline Lifetime alcohol intake, total units & s 1648 & $0-31589$ \\
\hline Gram-years of alcohol & 56 & 0-1019 \\
\hline Drinks per drinking day, units & 3 & $0-10$ \\
\hline Binge-drinking episodes per year & 1.2 & $0-45$ \\
\hline Drinks last week & 0 & $0-16$ \\
\hline Drinks last year & 27 & $0-1004$ \\
\hline
\end{tabular}

Table 1. Participant characteristics. Data are presented as median and range, or as

total number and per cent. Abbreviations: DM, diabetes mellitus. BMI, body mass

index. ALT, alanine aminotransferase. AST, aspartate aminotransferase. HOMA-IR, homeostatic model assessment - insulin resistance. hS-CRP, highly sensitive Creactive protein. LDL, low-density lipoprotein. NAS, NAFLD activity score. 


\begin{tabular}{|c|c|c|c|c|c|}
\hline \multirow[t]{2}{*}{ Variable } & \multicolumn{2}{|c|}{ Below median } & \multicolumn{2}{|c|}{ Above median } & \multirow[b]{2}{*}{ P-value } \\
\hline & Median/N (\%) & Range & Median/N (\%) & Range & \\
\hline Age at biopsy & 57.2 & $22.4-77.2$ & 54.6 & 19.3-72.1 & 0.17 \\
\hline $\begin{array}{l}\text { Sex, N male } \\
\text { (\%) }\end{array}$ & $33(55)$ & & $50(83)$ & & 0.001 \\
\hline \multicolumn{6}{|l|}{$\begin{array}{l}\text { Smoking, N } \\
\text { (\%) }\end{array}$} \\
\hline Never & 35 (59) & & $30(50)$ & & 0.61 \\
\hline Ever & $25(41)$ & & $30(50)$ & & \\
\hline $\begin{array}{l}\text { Coffee } \\
\text { consumption }\end{array}$ & 14 & $0-56$ & 14 & $0-70$ & 0.11 \\
\hline $\begin{array}{l}\text { Soft drink } \\
\text { consumption }\end{array}$ & 0 & $0-56$ & 0 & $0-42$ & 0.42 \\
\hline $\begin{array}{l}\text { DM type 2, N } \\
\text { (\%) }\end{array}$ & $28(47)$ & & 21 (35) & & 0.12 \\
\hline $\begin{array}{l}\text { Hypertension, } \\
\text { N (\%) }\end{array}$ & 35 (59) & & $27(45)$ & & 0.08 \\
\hline BMI & 30.5 & $23.1-44.2$ & 29.4 & $20.3-45-3$ & 0.42 \\
\hline Waist (cm) & 104 & 86-133 & 107 & 88-193 & 1 \\
\hline Hip (cm) & 106 & $90-140$ & 106 & $91-138$ & 0.63 \\
\hline Ferritin $(\mu \mathrm{g} / \mathrm{L})$ & 239 & $7-1804$ & 289 & $18-1090$ & 0.97 \\
\hline ALT (IU/L) & 55 & $18-231$ & 61 & $20-292$ & 0.22 \\
\hline AST (IU/L) & 44 & $22-147$ & 44 & $17-88$ & 0.76 \\
\hline $\begin{array}{l}\text { Fasting } \\
\text { Glucose } \\
\text { (mg/dL) }\end{array}$ & 123 & $85-703$ & 118 & $88-243$ & 0.31 \\
\hline HOMA-IR & 10.6 & $1.5-135.2$ & 8.5 & 2.8-389.5 & 0.25 \\
\hline $\begin{array}{l}\mathrm{HbA1c} \\
(\mathrm{mmol} / \mathrm{mol})\end{array}$ & 44 & 23-105 & 38 & 26-90 & 0.98 \\
\hline $\begin{array}{l}\text { hS-CRP } \\
\text { (mg/L) }\end{array}$ & 2.7 & $0.2-30.1$ & 1.5 & $0.2-11.2$ & 0.004 \\
\hline TNF (ng/L) & 9.7 & $6.6-17.6$ & 7.9 & $5.4-14.9$ & 0.05 \\
\hline $\begin{array}{l}\text { Cholesterol } \\
\text { (mg/dL) }\end{array}$ & 170 & 93-309 & 193 & 93-301 & 0.03 \\
\hline LDL (mg/dL) & 96 & $35-212$ & 116 & $31-205$ & 0.05 \\
\hline HDL (mg/dl) & 42 & $12.0-77.0$ & 43 & $31-89$ & 0.45 \\
\hline $\begin{array}{l}\text { Triglycerides } \\
\text { (mg/dL) }\end{array}$ & 159 & $65-478$ & 150 & $42-425$ & 0.45 \\
\hline NAS (0-8) & 4 & $1-8.0$ & 4 & $1-7.0$ & 0.55 \\
\hline $\begin{array}{l}\text { Fibrosis stage, } \\
\text { N (\%) }\end{array}$ & & & & & 0.03 \\
\hline 0 & $5(8)$ & & $15(25)$ & & \\
\hline 1 & $24(40)$ & & $21(35)$ & & \\
\hline 2 & $8(13)$ & & $13(22)$ & & \\
\hline 3 & $11(18)$ & & $6(10)$ & & \\
\hline 4 & $12(20)$ & & $5(8)$ & & \\
\hline
\end{tabular}


Lifetime

alcohol intake

per week, units

$\begin{array}{lllll}0.27 & 0-1.13 & 3.19 & 1.14-13.2 & <0.001\end{array}$

Lifetime

alcohol intake,

total units

Gram-years of

alcohol

$0-3138$

6598

$540-31589<0.001$

Drinks per

drinking day,

units

0-101

201

16-1019 <0.001

Binge-drinking

episodes per

year

2

$0-10.0$

4.3

$1.7-9.9$

$<0.001$

Drinks last

week

0-7

4

0-45

$<0.001$

Drinks last

year 19

0

0-15

2

$0-16$

$<0.001$

Table 2. Participant characteristics stratified on median weekly lifetime alcohol consumption (1.1 units/week). Data are presented as median and range, or as total number and per cent. Abbreviations: DM, diabetes mellitus. BMI, body mass index. ALT, alanine aminotransferase. AST, aspartate aminotransferase. HOMA-IR, homeostatic model assessment - insulin resistance. hS-CRP, highly sensitive Creactive protein. LDL, low-density lipoprotein. NAS, NAFLD activity score. 


\begin{tabular}{|c|c|c|c|c|}
\hline Variable & OR, 95\% CI & P-value & aOR, 95\% CI & P-value \\
\hline $\begin{array}{l}\text { Units of alcohol per } \\
\text { week }^{1}\end{array}$ & $0.86,0.77-0.97$ & 0.016 & $0.86,0.76-0.97$ & 0.017 \\
\hline $\begin{array}{l}\text { Diabetes mellitus type } \\
2\end{array}$ & $2.91,1.40-6.05$ & 0.004 & $2.63,1.13-6.14$ & 0.025 \\
\hline Hypertension & $2.21,1.10-4.47$ & 0.027 & $1.35,0.55-3.30$ & 0.51 \\
\hline $\mathrm{BMI}^{1}$ & $1.06,0.98-1.14$ & 0.15 & $1.04,0.97-1.13$ & 0.28 \\
\hline Smoking, ever & $1.46,1.01-2.09$ & 0.042 & $1.26,0.84-1.89$ & 0.27 \\
\hline Age at biopsy ${ }^{1}$ & $1.02,1.00-1.04$ & 0.042 & $1.00,0.97-1.03$ & 0.84 \\
\hline $\begin{array}{l}\text { Gram-years of } \\
\text { alcohol }^{2}\end{array}$ & $0.52,0.26-1.05$ & 0.07 & $0.43,0.20-0.94$ & 0.04 \\
\hline PEth $(\mu \mathrm{mol} / \mathrm{L})$ & $2.76,1.06-7.21$ & 0.038 & $2.77,1.01-7.59$ & 0.047 \\
\hline $\begin{array}{l}\text { Last year total alcohol } \\
\text { intake }\end{array}$ & $1.00,0.99-1.00$ & 0.26 & - & - \\
\hline $\begin{array}{l}\text { Last week total } \\
\text { alcohol intake }\end{array}$ & $0.94,0.84-1.05$ & 0.26 & - & - \\
\hline $\begin{array}{l}\text { Drinks per drinking } \\
\text { day }^{1}\end{array}$ & $0.95,0.82-1.10$ & 0.46 & - & - \\
\hline $\begin{array}{l}\text { Number of binges per } \\
\text { year }^{1}\end{array}$ & 0.97, 0.93-1.01 & 0.11 & - & - \\
\hline AUDIT score ${ }^{1}$ & $1.01,0.88-1.17$ & 0.86 & - & - \\
\hline Coffee consumption ${ }^{3}$ & $1.01,0.98-1.03$ & 0.67 & - & - \\
\hline $\begin{array}{l}\text { Soft drink } \\
\text { consumption }^{3}\end{array}$ & $1.00,0.96-1.03$ & 0.81 & - & - \\
\hline Physical activity ${ }^{4}$ & $0.87,0.64-1.20$ & 0.40 & - & - \\
\hline
\end{tabular}

Table 3. Crude and adjusted odds ratios for increasing fibrosis stage. ${ }^{1}$ For each unit increase ( 1 unit equals 12 grams of alcohol). ${ }^{2}$ More vs. less than the median of 56 gram-years ${ }^{3}$ For each unit increase per week. ${ }^{4}$ For each step increase on the 6-digit scale. Abbreviations: OR, odds ratio. CI, confidence interval. aOR, adjusted odds ratio. BMI, body mass index. PEth, phosphatidyl ethanol. AUDIT, alcohol use disorders identification test. 


\begin{tabular}{lll}
\hline Variable & OR, 95\% CI & P-value \\
\hline Units of alcohol per week $^{1}$ & $0.98,0.86-1.11$ & 0.71 \\
Diabetes mellitus type 2 & $1.01,0.46-2.22$ & 0.99 \\
Hypertension & $1.06,0.49-2.32$ & 0.88 \\
BMI $^{1}$ & $1.08,0.99-1.18$ & 0.09 \\
Smoking, ever $^{\text {Age at biopsy }}$ & $0.66,0.43-1.00$ & 0.05 \\
Drinks per drinking day $^{1}$ & $1.01,0.98-1.04$ & 0.48 \\
Gram-years of alcohol $^{2}$ & $0.99,0.83-1.17$ & 0.9 \\
Number of binges per year $^{1}$ & $0.90,0.41-1.97$ & 0.79 \\
PEth $\geq 0.3 \mu$ mol/L & $0.99,0.95-1.04$ & 0.79 \\
\hline
\end{tabular}

Table 4. Crude odds ratios in association with NASH defined as per the FLIP

algorithm. ${ }^{1}$ For each step increase. ${ }^{2}$ More vs. less than the median of 56 gram-years.

Abbreviations: OR, odds ratio. CI, confidence interval. BMI, body mass index. PEth, phosphatidyl ethanol. 
Figure legends.

Fig 1. Scatterplot of reported lifetime consumption of units of alcohol per week versus fibrosis stage including $95 \%$ confidence intervals. $N=107 . R^{2}=-0.22$ using Spearman’s rho. 


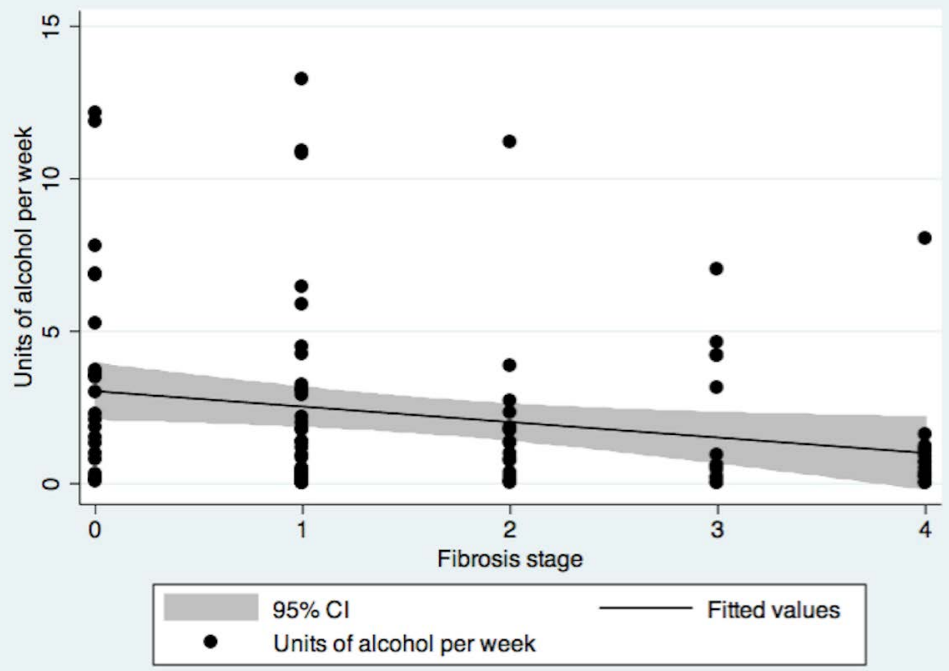

